\title{
El turista ante el factor riesgo. Consideraciones acerca del turismo activo y su esfera de protección ${ }^{1}$
}

\author{
Dr. D. Nicolás Alejandro Guillén Navarro
}

Director de la Escuela de Turismo Universitaria de Zaragoza

\begin{abstract}
SUMARIO: I. El turismo activo y su práctica en el medio natural. II. El inicio de la actividad y la seguridad del turista. III. El control en el desarrollo de la actividad. IV. El turista y el factor riesgo. Responsabilidad civil derivada del ejercicio de actividades en el ámbito del turismo activo. V. La responsabilidad patrimonial de la Administración pública.- VI. Tasa por movilización de efectivos y medios de emergencia. VII. Consideraciones finales. VIII. Bibliografía.
\end{abstract}

\section{RESUMEN}

El auge del turismo activo en España conlleva la necesidad de analizar hasta qué punto la normativa tiene presente las especiales peculiaridades de esta tipología turística. El desarrollo de actividades en la naturaleza y la existencia con ello de un componente de riesgo para el turista son aspectos que no pueden pasar desapercibidos y que requieren un tratamiento jurídico adecuado. El control administrativo de la actividad de las empresas de turismo activo, tanto a la hora de iniciar su actividad, como en su desarrollo, de las actividades son elementos imprescindibles que ayudan a generar una esfera de protección sobre el turista, todo ello sin obviar la problemática en cuanto a la responsabilidad de la empresa ante accidentes sufridos por los turistas.

Estudio realizado en el marco del proyecto I+D 2015 (DER 2015-6734) "Regulación y mecanismos de mercado para la protección ambiental en Derecho administrativo" del área de derecho administrativo de la Universidad de Zaragoza. 


\section{PALABRAS GLAVE:}

Responsabilidad patrimonial, responsabilidad civil, factor riesgo, deportes de riesgo, turismo de aventura.

\section{ABSTRACT}

The boom of adventure tourism in Spain implies the need to analyze this new type of tourism. The practice of activities in the natural environment and the existence of an element of risk for tourists are aspects that cannot be ignored and require proper legal treatment. The administrative control of the activity of active tourism companies is essential because it helps to create a scope of safety for tourists, without forgetting the responsibility of the company for the accidents suffered by tourists.

\section{KEY WORDS:}

State liability, civil liability, risk factor, extreme sports, active tourism.

\section{EL TURISMO ACTIVO Y SU PRÁCTICA EN EL MEDIO NATURAL}

El turismo activo es una tipología turística de reciente aparición en España. Su orígen normativo hay que remontarlo, a los años noventa cuando la Comunidad Autónoma de Cataluña recoge por primer vez dicha figura, asociando la misma a la realización de actividades sirviéndose de los recursos naturales y a las que es inherente el factor riesgo ${ }^{2}$. Su regulación a través del Decreto 81/1991, de 25 marzo, por el que se regulan los requisitos de empresas de organización de actividades deportivas de recreo y turísticas de aventura, daba idea clara de la vinculación con las actividades deportivas, incorporándose a su vez un conjunto reducido de actividades que delimitaban el ámbito de esta modalidad, más que turística, deportiva ${ }^{3}$.

Sí que es verdad que a la hora de concretar qué se entiende por turismo activo, surge la pregunta si realmente se circunscribe únicamente al aspecto turístico. En este sentido, ya no sólo Cataluña ha optado por vincular, como se ha señalado antes,

\footnotetext{
$2 \quad$ Decreto 81/1991, de 25 marzo, por el que se regulan los requisitos de empresas de organización de actividades deportivas de recreo y turísticas de aventura. En este mismo sentido, NASARRE SARMIENTO, José María (2012): 233-263. La tardía aparición de este tipo de turismo ha conllevado que el escaso tratamiento doctrinal del mismo destacándose en sus orígenes los trabajos de MELGOSA ARCOS, Francisco Javier (1999): 477-502 y ASPAS ASPAS, José Manuel (2000).

3 Norma que debía completarse con la Orden de 10 de abril 1991, por la que se regulaban las actividades deportivas de recreo y turísticas de aventura, en la que se recogían catorce actividades a las que era de aplicación el Decreto 81/1991, de 25 marzo: parapente, bicicleta todo terreno (mountain bike); descenso de barrancos; descenso en bote (rafting); esquí de río (river-ski); heliesquí (heli-ski); heliexcursión (heli-trip); hibrobob; hidrotrineo (hydrospeed); marcha en caballo (horseback); piragüismo (canoe kayak); salto desde el puente/puentismo (puenting); salto con elástico; trekking.
} 
el turismo activo con el ámbito deportivo, hecho que mantiene en la actualidad, sino que otras Comunidades Autónomas, como la Comunidad Foral de Navarra, históricamente lo han llegado a asociar con el ámbito medioambiental. Tal situación viene dada por la discrepancia en cuanto a su delimitación conceptual que incluso confluye con otros términos como el turismo de naturaleza o el ecoturismo que de nada ayuda a recoger una idea clara del mismo ${ }^{4}$. Así, el Real Decreto 1274/2011, de 16 de septiembre, por el que se aprueba el Plan estratégico del patrimonio natural y de la biodiversidad 2011-2017, define al turismo de naturaleza como aquel vinculado a la "realización de actividades recreativas y de esparcimiento, la interpretación y/o conocimiento de la naturaleza, con diferente grado de profundidad y la práctica de actividades deportivas de diferente intensidad física y riesgo que usen expresamente los recursos naturales de forma específica, sin degradarlos o agotarlos", un concepto amplio que engloba algo más que el simple disfrute o conocimiento del entorno natural.

Acudiendo a la normativa autonómica sobre turismo activo, indicando que no todas cuentan con regulación específica ${ }^{5}$, se desprende la consideración mayoritaria de que las actividades de turismo activo son aquellas que se practican sirviéndose básicamente de los recursos que ofrece la propia naturaleza en el medio en el que se desarrollan, ya sea aéreo, terrestre de superficie, subterráneo o acuático y a las que es inherente el factor riesgo o cierto grado de esfuerzo físico o de destreza para su práctica. No obstante, hay que señalar que no sólo se debe pensar que el turismo ac-

\footnotetext{
4 Acerca de la confluencia con otras tipologías de turismo como el de naturaleza o el de aventura, LACOSTA ARAGÜÉS, Antonio Javier (2004): 11-31; PEÑALVER TORRES, María Teresa (2004): 179215; VILA FRADERA, Jorge (1997).

5 Andalucía: Decreto 20/2002, de 29 de enero, que regula la prestación de servicios en el medio rural y el turismo activo; Aragón: Decreto 55/2008, de 1 de abril, del Gobierno de Aragón, por el que se aprueba el Reglamento de las empresas de Turismo Activo; Cantabria: Decreto 31/1997, de 23 de abril, de Cantabria, sobre alojamientos y actividades turísticas en el medio rural (derogado parcialmente); Castilla-La Mancha: Decreto 77/2005, de 28 de junio, de ordenación de las empresas de turismo activo; Castilla y León: Decreto 96/2007, de 27 de septiembre, por el que se regula la Ordenación de las Empresas de Turismo Activo de la Comunidad de Castilla y León, Orden CYT/1865/2007, de 15 de noviembre, por la que se desarrolla el Decreto 96/2007 de 27 de septiembre, por el que se regula la Ordenación de las Empresas de Turismo Activo de la Comunidad de Castilla y León; Cataluña: Decreto 56/2003, de 4 de febrero, que regula las actividades fisico-deportivas en el medio natural; Comunidad Foral de Navarra: Decreto Foral 288/2004, de 23 de agosto, por el que se aprueba el reglamento para el ejercicio de la actividad de las empresas dedicadas a la prestación de servicios de turismo activo y cultural; Comunidad Valenciana; Decreto 22/2012, de 27 de enero, del Consell, regulador del turismo activo en la Comunitat Valenciana; Galicia: Decreto 42/2001, de 1 de febrero, por el que se refunde la normativa de agencias de viajes, guías de turismo especializado y turismo activo; Islas Baleares: Decreto 20/2015, de 17 de abril, de principios generales y directrices de coordinación en materia turística; de regulación de órganos asesores, de coordinación y de cooperación del Gobierno de las Illes Balears, y de regulación y clasificación de las empresas y de los establecimientos turísticos, dictado en desarrollo de la Ley 8/2012, de 19 de julio, de Turismo de las Illes Balears (arts. 117 a 124); La Rioja: Decreto 14/2011, de 4 de marzo, por el que se por el que se aprueba el Reglamento de desarrollo de la Ley 2/2001, de 31 de mayo, de Turismo de La Rioja; Principado de Asturias: Decreto $111 / 2014$, de 26 de noviembre, de Turismo Activo; Región de Murcia: Decreto 320/2007, de 19 de octubre, por el que se regulan las empresas de turismo activo de la Región de Murcia.
} 
tivo se centra en realización de actividades deportivas en el medio natural, sino que normativas como la murciana (art. 2 del Decreto 320/2007, de 19 octubre) amplían este marco al englobar la explotación turística de los recursos de contenido cultural, recreativo, deportivo y de ocio, además de itinerarios con fines eminentemente turísticos.

Es de común acuerdo excluir del ámbito normativo del turismo activo y por tanto no tienen consideración de empresas de turismo activo a los clubes y federaciones deportivas siempre y cuando organicen actividades en el medio natural, dirigidas única y exclusivamente a sus asociados o afiliados y no al público en general $^{6}$. Sin embargo, más problemático resulta encuadrar a las empresas cuyas actividades se limitan a la venta, arrendamiento o préstamo de uso del material necesario para su práctica. Así, regulaciones como la asturiana o la castellano-manchega engloban estas actividades en el de turismo activo y por lo tanto afectadas por la regulación, si bien este criterio no es unánime ya que, por ejemplo, la Comunidad Valenciana las excluye del ámbito de aplicación de la norma ${ }^{7}$.

Atendiendo a los planteamientos anteriormente expuestos parece coherente considerar que el objetivo del turismo activo es el de aprovechar los recursos que ofrece la naturaleza en todas sus dimensiones para el desarrollo personal, lúdico, cultural o deportivo de la persona que realiza la actividad concreta, requiriendo para ello un comportamiento activo en su práctica, asumiéndose cierto grado de riesgo en su realización y careciendo en todo caso de un carácter competitivo. De esta consideración sobresalen dos aspectos como es el denominado factor riesgo y el medio natural, siendo necesario acudir al marco normativo para ver cómo se delimitan ambos conceptos.

Resulta interesante el hecho de que las normativas no recogen una definición de ambos (riesgo natural y medio natural), siendo la normativa catalana una de las excepciones. Por lo que respecta al componente riesgo, sin duda es relevante la consideración hecha por la regulación catalana en donde se asocia directamente al medio natural al indicarse que la práctica de dichas actividades puede resultar afectada y condicionada por "factores meteorológicos, por el ecosistema, y por otras dificultades del medio, por lo que representan un cierto riesgo para las personas que las practican" (art. 1.2.c. del Decreto 56/2003, de 4 de febrero). De ello debe extraerse

$6 \quad$ Entre otras, Aragón (art. 2.3 del Decreto 55/2008, de 1 abril); Castilla La Mancha (art. 3.3 del Decreto 77/2005, de 28 junio); Comunidad Foral de Navarra (art. 3.2.a del Decreto Foral 288/2004, de 23 agosto); Comunidad Valenciana (art. 3.2 del Decreto 22/2012, de 27 enero); Región de Murcia (art. 2.2 del Decreto 320/2007, de 19 octubre).

7 Castilla La Mancha (art. 2.1 del Decreto 77/2005, de 28 junio); Comunidad Valenciana (art. 3.3 del Decreto 22/2012, de 27 enero); Principado de Asturias (art. 4 del Decreto 111/2014, de 26 noviembre). 
lo imprevisible que resulta la realización de las mismas y la existencia de numerosos factores ajenos ya no sólo a la persona que lo práctica, sino a los monitores o guías responsables de la tutela en su ejecución. De todas maneras, si el factor riesgo es un elemento necesario, no lo es menos el medio natural, entendido como "aquellos espacios de menor o mayor extensión que contienen uno o más ecosistemas no esencialmente transformados por la explotación y ocupación humanas, y pueden representar un riesgo de deterioro de este medio natural".

El papel que juegan estos factores viene a determinar en gran medida los requisitos que deben reunir las empresas de turismo para poder llevar a cabo su actividad y que abarcan aspectos tan diversos como la formación de sus monitores o guías o el material a utilizar. No obstante, ello no se detiene ahí, sino que a su vez se establecen toda una serie de deberes y obligaciones tanto para usuarios, como para las empresas, que abarcan desde las condiciones físicas o edad de los primeros o las medidas de respeto medioambiental para ambos, aspectos que serán analizados más adelante.

Hay que señalar también que el número de actividades a englobar dentro del turismo activo va en aumento, dejando obsoleto el listado de apenas catorce actividades que recogía la Orden catalana de 10 de abril $1991^{8}$. En relación a este aspecto, destaca sobre todo la inexistencia de un listado tasado de actividades a englobar dentro del turismo activo, dependiendo en todo caso de la consideración hecha por cada

${ }_{8}$ Un resumen de las actividades que se pueden encontrar referenciadas en España puede ser el siguiente: actividades subacuáticas (buceo / escafandrismo / snorkel); actividades náuticas (bodyboard / canoa / charter náutico / busbob-hidrobob / donutski / esquí de río/ esquí acuático / hidropedales / hidrospeed / hidrotrineo / kayak / kite surf /motos de agua / paseo turístico desde embarcación / paipo / paradescending / piragüismo / rafting / ski bus / stand up paddle / surf / vela ligera / vela crucero / windsurf / wakeboard); hípica (turismo ecuestre / paseos con otros animales); ciclismo (mountain bike / cicloturismo); actividades aéreas (ala delta / banging / globo aerostático / heliexcursión / paracaidismo / parapente / puenting / vuelo con motor / vuelo sin motor / vuelo con ultraligero); actividades de montaña y escalada (alpinismo / barranquismo / circuito multiactividad / descenso de cañones / escalada en roca, hielo y rocódromo / montañismo / parque de aventura / puente mono / puente tibetano / rápel / tirolina / vía ferrata); rutas a pie (senderismo / trekking / itinerarios didácticos e interpretativos); orientación (carrera de orientación / actividad de orientación; taller de medio ambiente y naturaleza (observación de flora y fauna / visitas a cuevas); ruta cultural; agroactividad; ruta temática; espeleología; tiro con arco; actividades de nieve (escuelas de esquí / esquí alpino / esquí de fondo / esquí de travesía / esquí fuera de pistas / excursiones con raquetas de nieve / heliesquí / marcha nórdica / motos de nieve / mushing / snowboard); rutas o excursiones con vehículos a motor (buggies / enduro / trial / quads / ruta en vehículo 4×4); paintball / airsoft; supervivencia; deportes autóctonos; team building; otras actividades (caza turística / pesca turística desde embarcación en mar/ pesca turística; zorbing. Destaca el hecho de que gran parte de las actividades se identifica a través de anglicismos por lo que alguna normativa opta por introducir una pequeña traducción explicativa (Principado de Asturias) a no ser que se hayan definido cada una de las actividades como ocurre Aragón o en la Región de Murcia. Un estudio acerca del léxico asociado a las diferentes disciplinas que integran el turismo activo se puede encontrar en ESTORNELL PONS, María (2003: 33-55). 
una de las Comunidades Autónomas. La mayoría de las regulaciones autonómicas optan por incluir un anexo de actividades más o menos amplio que en muchos casos simplemente es ordenado de manera alfabética (Castilla La Mancha o Comunidad Valenciana $)^{9}$. Asimismo, no debe pensarse que el turismo activo es la realización de actividades dificultosas y con un alto factor de riesgo, véase el rafting, puenting o el buceo, sino que en la búsqueda de la satisfacción de la cada vez más exigente demanda turística se ha abierto el abanico a una variada oferta como ocurre en la Región de Murcia donde dentro del catálogo de actividades se incluye la realización de rutas en barco a motor, itinerarios didácticos e interpretativos, talleres de medio ambiente y naturaleza, rutas culturales, rutas temáticas o la agroactividad. Dicha evolución se pone en consonancia con el planteamiento de la Organización Mundial del Turismo a la hora de delimitar el denominado adventure tourism, adoptando a su vez el concepto utilizado por la Adventure Travel Trade Association ${ }^{10}$. Así, si en el caso del turismo activo existe una vinculación con el factor riesgo y el medio natural, este "turismo de aventura" se asocia a cualquier viaje o actividad que reúna al menos dos de los siguientes tres factores: actividad física, medio natural e inmersión cultural. Esta interpretación lleva a considerar a esta tipología de turismo como algo más que la práctica de deportes de aventura, incluyendo otras actividades como la observación de aves, la realización de safaris, la visita de sitios históricos o el desplazarse a un lugar para aprender una nueva lengua. Al fin y al cabo la consideración de turismo de aventura vendrá dado por lo que supone la adquisición de una nueva experiencia/aventura para el individuo, por lo que se aprecia un importante componente subjetivo y por lo tanto la inexistencia de un criterio uniforme al respecto ${ }^{11}$.

9 De modo negativo destaca la regulación gallega (disposición adicional segunda del Decreto 42/2001, de 1 de febrero) que no llega ni a la decena de actividades a englobar dentro del turismo activo: parapente, ala delta, descenso de barrancos, descenso en bote, hidrotrineo, piragüismo, puenting, salto con elástico, escalada.

10 WORLD TOURISM ORGANIZATION (2014) y ADVENTURE TRAVEL TRADE ASSOCIATION (2013).

1 Vid. BUCKLEY, Ralf (2010) y BEARD, Colin; SWARBROOKE, John; LECKIE, Suzanne y POMFRET, Gill (2003). 


\section{EL INICIO DE LA ACTIVIDAD Y LA SEGURIDAD DEL TURISTA}

En el compendio normativo del turismo activo, la protección del usuario torna en esencial y se traduce en distintas medidas que comienzan ya en la fase de inicio de la actividad de la empresa de turismo activo y que se asocian fundamentalmente a cuestiones relativas a la seguridad y ciertas peculiaridades relativas a la esfera contractual.

En cuanto al inicio de la actividad, de conformidad con la Directiva 2006/123/ $\mathrm{CE}$, las normativas sobre turismo activo vinculan la misma al régimen de declaración responsable o comunicación previa con lo que una vez presentada, la empresa puede iniciar la actividad siempre y cuando cuente con las licencias o autorizaciones exigidas por otros organismos en virtud de sus respectivas competencias, atendiendo a la legislación sectorial con vínculos sobre el turismo activo. No obstante, sí que es verdad que hasta fechas recientes se advertían discrepancias en relación a los trámites previos a seguir para la prestación de servicios de turismo activo, encontrándose la utilización tanto de la declaración responsable o comunicación previa, como la autorización administrativa previa al inicio de la actividad, caso que ocurría en Aragón $^{12}$, si bien el artículo 37.5 de la Ley 2/2016, 28 enero, de Medidas Fiscales y Administrativas de la Comunidad Autónoma de Aragón, vino a suprimir la autorización turística, equiparando esta Comunidad Autónoma con el resto en cuanto a este aspecto ${ }^{13}$. Por otra parte, hay que tener presente la libertad respecto a la prestación de servicios

12 Profundizando en las razones, el derogado art. 26 del Decreto Legislativo 1/2013, de 2 de abril, del Gobierno de Aragón, por el que se aprueba el texto refundido de la Ley del Turismo de Aragón, aludía a la salvaguarda de la "seguridad pública, la protección civil y la conservación del medio ambiente", circunstancias merecedoras de un control por parte de la Administración pública y que impiden por tanto que pueda realizar la actividad turística hasta que no se haya concedido dicha autorización. Cuando se habla de razones imperiosas de interés general, éstas se asocian a diversos ámbitos, los cuales se interpretan de acuerdo con la jurisprudencia del Tribunal de Justicia de la Unión Europea relativa a los arts. 43 y 49 del Tratado de Roma. Vid. BERMEJO LATRE, José Luis y ESCARTÍN ESCUDÉ, Víctor (2010: 495-512). Acerca de la influencia de la directiva de servicios de mercado interior en la regulación del turismo en España se puede consultar el interesante estudio de MELGOSA ARCOS, Francisco Javier (2013: 73-96).

13 Vid. Castilla y León: art. 21 Ley 14/2010, de 9 diciembre, de turismo de Castilla y León; Comunidad Foral de Navarra: art. 9 del Decreto 14/2011, de 4 marzo, por el que se aprueba el Reglamento de desarrollo de la Ley de Turismo de La Rioja; Principado de Asturias: art. 5 del Decreto 111/2014, de 26 noviembre; Región de Murcia, arts. 20 y 40 de la Ley 12/2013, de 20 diciembre, por la que se aprueba la Ley de Turismo de la Región de Murcia). Resulta curiosa sin duda la redacción del art. 27 del Decreto Legislativo 1/2013, de 2 de abril, en donde como se hacía con la autorización previa se vincula la declaración responsable a la "salvaguarda del orden público, la seguridad pública, la protección civil, la salud pública, la protección del medio ambiente, del entorno urbano y del patrimonio histórico-artístico, y respetando el principio de proporcionalidad, para la apertura, clasificación y, en su caso, reclasificación de los establecimientos turísticos, así como para el ejercicio o la prestación de actividades o servicios turísticos". 
por parte de empresarios turísticos de otras Comunidades Autónomas o incluso de otros Estados miembros de la Unión Europea que quieran prestar servicios en otro territorio. Teniendo en cuenta la aprobación de la Directiva de servicios, el marco normativo actual ofrece facilidades en cuanto a la tramitación y autorización de dicha actividad, situación que conlleva a que las empresas puedan establecerse sin necesidad de presentar dicha declaración (Castilla y León art. 21 Ley 14/2010, de 9 diciembre) o simplemente presentar una declaración responsable que se refiera únicamente "a la adecuación del establecimiento físico a los requisitos y condiciones exigibles, incluidos los relativos a seguros y fianzas" (Principado de Asturias: art. 5.3 Decreto $111 / 2014$, de 26 noviembre) $)^{14}$.

Profundizando ya en los requisitos que debe reunir una empresa de turismo activo para iniciar su actividad, es interesante comprobar cómo el desarrollo de las actividades en la naturaleza y la vinculación a un factor riesgo tiene como consecuencia un control severo sobre la actividad de las empresas y los medios con los que cuenta con el objeto sobre todo de articular una esfera de seguridad que asegure el correcto disfrute de la actividad que va a desarrollar el turista. Ello se aprecia en distintos aspectos como la titulación que deben tener los responsables de empresa y los monitores o guías; la disposición de equipos y materiales homologados por los órganos competentes; la figura del seguro de responsabilidad civil, de asistencia o de accidente; los protocolos de actuación en caso de accidente, la inscripción en el Registro o las placas identificativas con las que debe contar la empresa. Todos estos aspectos no quedan como simples trámites, sino que su control y ejecutividad se prolongan adquiriendo especial relevancia durante el funcionamiento de la empresa y la realización de actividades por parte de los clientes.

En cuanto a los requisitos formativos de los monitores, guías e instructores que desempeñan su labor en una empresa de turismo activo, se impone el hecho de que la empresa cuente entre su personal con técnicos o monitores con conocimientos específicos o adecuados en función de la actividad de que se trate. Este criterio se asocia a que estos monitores o guías cuenten con los títulos de técnico deportivo o técnico deportivo superior en la modalidad correspondiente ${ }^{15}$, figura regulada a través Real Decreto 1363/2007, de 24 de octubre, por el que se establece la ordenación general de las en-

14 Esta situación viene en consonancia con lo dispuesto en los arts. 19 y 20 de la Ley 20/2013, de 9 de diciembre, de garantía de la unidad de mercado, por los cuales cualquier producto o servicio producido al amparo de cualquier normativa autonómica puede ser ofertado o prestado en todo el territorio nacional sin necesidad de trámite adicional, salvo en algunos casos. Acerca de la incidencia de dicha norma, PADRÓS I REIG, Carlos y MACÍAS CASTAÑO, José María (2014): 113-151. TORNOS MAS, Joaquín (2014): 144-177.

15 Entre otras: Aragón (art. 9 Decreto 55/2008, de 1 de abril) y Castilla-La Mancha (art. 12 del Decreto 77/2005, de 28 de junio) o La Rioja (art. 209 del Decreto 14/2011, de 4 marzo). 
señanzas deportivas de régimen especial, hecho al que hay que sumar la formación exigida por la legislación aeronáutica, náutica y subacuática para la instrucción o acompañamiento de clientes en la práctica de actividades aéreas, náuticas o subacuáticas, además del título de socorrista o curso de primeros auxilios ${ }^{16}$.

Otro aspecto importante a analizar es el relativo al equipo y el material que son puestos a disposición de los usuarios. Hay que tener en cuenta que el desarrollo de actividades en un entorno natural lleva unido un factor riesgo que implica la adopción de una serie de medidas y protocolos que aseguren al usuario el disfrute adecuado de dichas actividades. Sobre todo estos aspectos se centran en que tanto los equipos, como el material que se utiliza, deben de estar homologados o certificados por los órganos competentes y, en ausencia de homologación, reunir las condiciones de seguridad y garantías para el uso a que estén destinados según las indicaciones de su fabricante, pudiendo ser en todo caso objeto de inspección por parte de los servicios competentes en materia de turismo. En este sentido, por ejemplo en Aragón, se exige que las empresas de turismo activo acrediten documentalmente la homologación o certificación de los equipos y material o las indicaciones del fabricante relativas a condiciones de seguridad y garantías del material. Además, hay que tener en cuenta que los empresarios son responsables de mantener en condiciones de uso adecuado los equipos y material, y que el personal de la empresa y todas las personas que participan en cada una de las actividades deben disponer de los equipos y el material adecuados para su práctica con el objeto de garantizar la seguridad en su desarrollo y también para hacer frente a los riesgos y emergencias que sean previsibles ${ }^{17}$. Como se aprecia, la seguridad en el desempeño de la actividad es esencial, de ahí que algunas regulaciones indiquen el que dichos equipos y material puedan ser objeto de inspección o que incluso la empresa curse de manera anual una declaración responsable en la que conste el cumplimiento de todas estas circunstancias. De todos modos, torna necesario el que las empresas siempre inspeccionen y controlen los equipos y

16 Vid. Aragón (art. 9 del Decreto 55/2008, de 1 abril) o Islas Baleares (art. 122 del Decreto 20/2015, de 17 abril). En este sentido, algunas normativas dan la posibilidad de que se acredite el cumplimiento de dicho requisito disponiendo de alguna de las siguientes formaciones, ya sea la de socorrista acuático, expedido por federaciones nacionales o autonómicas de salvamento y socorrismo; socorrista, expedido por la Cruz Roja Española; los cursos de socorrista o primeros auxilios declarados de interés sanitario por la Administración sanitaria estatal o autonómica; títulos universitarios, títulos deportivos, títulos de formación profesional o diplomas federativos cuando se acredite en el currículo o plan de estudios que se han superado módulos o asignaturas de primeros auxilios (Aragón, disposición adicional segunda del Decreto 55/2008, de 1 abril).

17 Vid. entre otras, Andalucía (art. 28 del Decreto 20/2002, de 29 enero); Aragón (art. 10 del Decreto 55/2008, de 1 abril); Cataluña (art. 9 del Decreto núm. 56/2003, de 4 de febrero), Galicia (art. 46 del Decreto núm. 42/2001, de 1 de febrero), La Rioja (art. 210 del Decreto 14/2011, de 4 marzo); Región de Murcia (art. 4 del Decreto núm. 320/2007, de 19 de octubre). 
materiales antes de iniciar la actividad, dejando constancia de la realización de dicha inspección ${ }^{18}$.

En relación con los riesgos que se derivan tanto de la actividad de la empresa, como de la realización de actividades, se conexiona otra obligación como es que la empresa de turismo activo deba contar con una serie de seguros, un requisito necesario para poner iniciar su actividad y que deberán mantenerse en vigor durante todo el tiempo de prestación, exigiéndose incluso la presentación anual de la copia de la póliza y recibo vigentes a la Administración correspondiente. Acudiendo a la normativa autonómica se comprueba el hecho de que las empresas deben contar tanto con un seguro de responsabilidad civil patronal y profesional que cubra de forma suficiente los posibles riesgos imputables a la empresa por la oferta y práctica de las actividades de turismo activo, como un seguro de asistencia y de accidente.

Por lo que respecta al seguro de responsabilidad civil, la cobertura mínima por siniestro varía entre Comunidades Autónomas, oscilando para la póliza de seguro de responsabilidad civil por siniestro entre los 600.001 euros (Castilla La Mancha); 600.000 euros (Comunidad Valenciana, Comunidad Foral de Navarra, Castilla y León, Islas Baleares), 390.657,86 euros (Galicia), 300.507 euros (Principado de Asturias) o los 300.000 euros (La Rioja) ${ }^{19}$. A su vez, se suelen establecer coberturas mínimas por víctima como en el caso de Castilla La Mancha (150.250 euros) o Castilla y León (150.000 euros). No obstante, no es sólo en estos aspectos en donde se pueden encontrar diferencias, ya que en lo relativo a la franquicia existe de nuevo discrepancia entre Comunidades Autónomas que optan por la prohibición de la misma (Galicia, Comunidad Foral de Navarra) o el establecimiento de ésta con valores máximos como es el caso de Islas Baleares (1.000 euros), Principado de Asturias (602 euros) o Castilla La Mancha (600 euros $)^{20}$. Asimismo, es interesante resaltar que en relación a las coberturas de este tipo de seguros, la Región de Murcia establece un amplio abanico de riesgos, en los que además de los vinculados al ejercicio de la actividad,

18 Vid. Castilla La Mancha (art. 5 Decreto núm. 77/2005, de 28 de junio); Castilla y León (art. 5 Decreto núm. 96/2007, de 27 de septiembre) y Principado de Asturias (art. 9 del Decreto núm. 111/2014, de 26 de noviembre).

19 En el caso de Galicia además se especifica que esta cobertura tendrá que abarcar todos los perjuicios que se puedan derivar de posibles daños, incluyendo los personales, materiales y los económicos. El límite por daños personales será de 180.303,63 euros y por daños materiales de 60.101,21 euros (art. 43 del Decreto núm. 42/2001, de 1 de febrero).

20 Castilla La Mancha (art. 10 del Decreto núm. 77/2005, de 28 de junio ); Castilla y León: art 7 del Decreto 96/2007, de 27 septiembre Comunidad Foral de Navarra: art. 5 del Decreto Foral 288/2004, de 23 agosto Comunidad Valenciana: art. 7.1.b del Decreto 22/2012, de 27 enero; La Rioja: art. 206 del Decreto 14/2011, de 4 marzo; Principado de Asturias; Galicia: art. 43.c del Decreto 42/2001, de 1 febrero. En el caso de Galicia, se estipula que el límite por daños personales será de $180.303,63$ euros y por daños materiales de $60.101,21$ euros. 
deben incluirse los daños corporales, daños materiales, daños morales y perjuicios económicos causados (art. 12 del Decreto núm. 320/2007, de 19 de octubre).

En cuanto a los seguros de asistencia y de accidente, de nuevo las normativas discrepan ya no sólo en los riesgos a cubrir, indicándose por ejemplo en Castilla La Mancha o la Comunidad Foral de Navarra que entre los riesgos se debe comprender los gastos de rescate, sino también en lo referido a la cuantía mínima [Principado de Asturias (30.050 euros)] o la posibilidad de contar con franquicia en donde algunas Comunidades Autónomas establecen la misma como Aragón (150 euros) o Principado de Asturias (602 euros), frente a otras que la excluyen (Castilla La Mancha).

Por otra parte, hay que tener presente que cuando la empresa lleve a cabo un servicio de transporte privado, deberá contar con un seguro de responsabilidad civil que en el caso de Aragón se exige que tenga una cobertura ilimitada de la responsabilidad por los daños personales. En relación con esto último, conviene advertir que en el caso de que la empresa use un vehículo para los itinerarios y actividades, debe presentar a la Administración tanto la copia del seguro, como copia del permiso de circulación y tarjeta de características, ello sin olvidar el cumplimiento de la normativa sobre transporte. En este sentido, resulta interesante la redacción de la Ley 13/2007, de 17 mayo, de ordenación del transporte por carretera de Canarias, de donde se extrae que en los casos de que se produzca el desplazamiento de los clientes o del material especializado (piraguas, tablas de surf, equipos de buceo, parapente, etc.), la normativa vincula a las empresas la previa obtención de una autorización de transporte privado complementario, la cual queda limitada a trayectos entre la sede de la empresa, los establecimientos hoteleros de hospedaje de los clientes y los lugares de realización de la actividad de ocio o recreo. Además, dicha norma recoge la obligación de que los vehículos tengan un carácter mixto, separando con ello la zona de pasajeros con la de carga (habitáculos separados sin posibilidad de comunicación entre ellas); una capacidad máxima de 9 personas, incluido el conductor; la capacidad de carga máxima de $3.5 \mathrm{~kg}$. de M.M.A o que el coste de este transporte debe formar parte del total percibido por la actividad contratada ${ }^{21}$.

Aparte de todo lo anteriormente analizado, a lo que se puede sumar la acreditación de que la empresa disponga de una base de operaciones y de almacenamiento de material (Aragón), otro aspecto que las normativas autonómicas exigen de cara al inicio de actividad es la de contar con un protocolo de actuación en caso de accidentes o un plan de autoprotección que es remitido a la Administración y servicios de

21 Art. 72 de la Ley 13/2007, de 17 mayo. De igual manera debe atenderse al desarrollo reglamentario mediante el Decreto 72/2012, de 2 de agosto (art. 78). 
Protección $\mathrm{Civil}^{22}$. Este plan o protocolo tiene una importancia vital en el desarrollo de las actividades, como se verá más adelante, ya que articula en gran medida la acción de los monitores, guías o instructores.

Teniendo presente este conjunto de requisitos que la empresa debe aportar y acreditar para el inicio de actividad, conviene aludir también a dos aspectos interesantes como son la inscripción de la empresa en el Registro de Turismo, y la exhibición de placas identificativas. Puede decirse que ambos hechos son manifestación, de cara al turista, de la legalidad de la empresa con la que contratan los servicios, en contraposición a la existencia de intrusismo en dicho sector.

En cuanto a la inscripción en el Registro de Turismo, vista la declaración responsable presentada por parte de la empresa de turismo activo, se procede de oficio a la inscripción ya sea de la empresa o de la actividad en el Registro de empresas y actividades turísticas de la Comunidad Autónoma (en sus diferentes denominaciones), originando a su vez un número de registro que debe constar y figurar en lugar visible en la documentación, páginas web y publicidad de las empresas, cualquiera que sea el medio en que se efectúe $\mathrm{e}^{23}$. Esta inscripción conlleva además que la Administración facilite un ejemplar del libro de inspección turística y ejemplares de las hojas de reclamaciones turísticas.

Relacionado con el anterior aspecto se encuentra también la obligación marcada en algunas normativas de que la empresa exhiba una placa de identificación en el exterior del local o del centro base de operaciones con el número de inscripción en el Registro de Turismo autonómico correspondiente, lo cual ayuda no sólo al cliente, sino también a la Administración, a identificar su legalidad, facilitando de igual manera las labores de inspección turística ${ }^{24}$. Por lo que respecta al modelo de placa identificativa, resulta curioso la adopción de distintas soluciones. Por ejemplo, en Aragón o Principado de Asturias la placa se asocia con la figura de la rosa de los vientos (Aragón), a la que incluso se le añade un palo de remo y las letras TA (Principado de Asturias), hecho que se simplifica en la regulación balear con el distintivo conformado con las referidas letras.

${ }^{22}$ Entre otras, Aragón (art. 11 del Decreto 55/2008, de 1 abril); Castilla La Mancha (art. 6.2. del Decreto núm. 77/2005, de 28 de junio), Comunidad Valencia (art. 4.6.b.5º del Decreto núm. 22/2012, de 27 de enero) o Islas Baleares (art. 122 del Decreto núm. 20/2015, de 17 de abril).

23 Vid. Aragón, art. 7 del Decreto 55/2008, de 1 abril; Comunidad Valenciana, art. 4 del Decreto núm. 22/2012, de 27 de enero; Islas Baleares, art. 6 del Decreto 20/2015, de 17 abril; Principado de Asturias, art. 6 del Decreto núm. 111/2014, de 26 de noviembre; Región de Murcia, art. 12 del Decreto núm. $320 / 2007$, de 19 de octubre.

24 Vid. Aragón, art 15 del Decreto 55/2008, de 1 abril; Castilla La Mancha, art 9 del Decreto 77/2005, de 28 junio; Castilla León, art. 6 del Decreto 96/2007, de 27 septiembre; Comunidad Valenciana, art. 7.2 del Decreto 22/2012, de 27 enero. 
Si la exhibición de estas placas o distintivos vienen marcados por la normativa turística, la empresa puede también optar por otros asociados a la calidad turística de los servicios que ofrece. En la actualidad se puede encontrar diferente normativa "UNE" en gestión interna de servicios de esparcimiento, ocio y turismo activo (UNEISO 21101:2015; UNE-ISO 21103:2015; UNE-ISO/TR 21102:2015 IN) centrada en aspectos como el sistema de gestión, planificación, funcionamiento, evaluación del desempeño, información a facilitar a los participantes de las actividades, o liderazgo y competencias ${ }^{25}$. Su incidencia es relativa ya que en 2014 existían 14 empresas de turismo activo certificadas según los datos del Instituto para la Calidad Turística Española, si bien el hecho de contar con el sello de la marca Q de calidad turística es buen mecanismo de garantía de calidad de los servicios ofertados y de optimización para las empresas como indica GONZÁLEZ MENORCA et al. (2014): 69 y ss.

Por otra parte, hay que señalar que a pesar del cumplimiento por parte de las empresas de turismo de los requisitos establecidos por la normativa turística, no puede obviarse la obligación de contar con las correspondientes licencias o autorizaciones municipales, sectoriales, etc. En este sentido, la realización de las actividades puede verse vinculada al cumplimiento de otros requisitos establecidos por diferente legislación sectorial, principalmente con un componente medioambiental, sin el cual no pueden llevarse a cabo, de ahí la necesidad de analizar este aspecto y las consecuencias aparejadas para el desarrollo normal de las mismas. Se puede observar en la normativa autonómica, por ejemplo, la exigencia de contar con la autorización de navegación, otorgada por el organismo competente, en los casos en que la actividad se desarrolle en aguas de dominio público o el contar con la autorización concedida por la órgano administrativo competente en materia de medio ambiente en aquellos supuestos en que sea exigida por la normativa de protección de los espacios naturales, terrenos forestales y vías pecuarias, ello sin perjuicio de cualquier otra autorización administrativa exigida por la legislación aplicable (Andalucía, art. 23 del Decreto núm. 20/2002, de 29 de enero) como, por ejemplo, la normativa sobre transporte o incluso la legislación de carreteras para la práctica del puenting ${ }^{26}$.

\section{EL CONTROL EN EL DESARROLLO DE LA ACTIVIDAD}

Como se ha comprobado, las normativas autonómicas recogen toda una serie de requisitos como punto de partida para poder iniciar la actividad que deben ser completados con otros asociados al desarrollo de las actividades de turismo activo

25 Esta normativa sustituye a la antigua UNE 188003:2009. La norma UNE-ISO 21101:2015 se centra en sistema de gestión de la seguridad y requisitos; UNE-ISO 21103:2015 sobre información para los participantes y UNE-ISO/TR $21102: 2015$ IN acerca de la competencia del personal.

${ }_{26}$ Acerca de las vinculaciones del turismo activo con el medio ambiente, desde distintos puntos de vista (sostenibilidad, sector privado, instrumentos de planificación) se pueden consultar los trabajos de 
que tienen un componente contractual y en el que se insertan los derechos y deberes de los turistas.

Se debe partir del hecho de cuando se habla de realización de las actividades, la vinculación entre la empresa y usuario/a se formaliza a través de un contrato que debe recoger el desglose de los servicios prestados y, sobre todo, el precio a abonar. A su vez, este contrato se complementa con el deber de la empresa de informar por escrito de distintos aspectos que en el caso de Aragón (art 12 del Decreto 55/2008, de 1 abril), por ejemplo, se concreta en los relativos a los destinos, itinerario o trayecto a recorrer ${ }^{27}$; medidas que deben adoptarse para preservar el entorno; equipo y material que debe ser aportado por el cliente; conocimientos necesarios, dificultad de la actividad y edad mínima para su práctica; existencia de una póliza de responsabilidad civil y de seguros de asistencia o accidentes; información de los precios de los servicios ofertados; condiciones especiales exigidas para la práctica de determinadas actividades; o la existencia de hojas de reclamaciones.

Para asegurarse de que toda esta información ha sido facilitada al cliente, el contrato suele incorporar una declaración expresa de haber recibido y aceptado la misma, y el compromiso de cumplir con las instrucciones de seguridad, protección ambiental o de buena práctica deportiva que se emitan (entre otras, Comunidad Valenciana, art. 11 del Decreto 22/2012, de 27 enero). En relación con este último aspecto, la vinculación contractual lleva consigo además el hecho que el cliente venga obligado al cumplimiento de otros aspectos como el abono del precio o el comunicar cualquier aspecto importante relativo a su condición física que pueda afectar en el desarrollo adecuado de la actividad (Principado de Asturias, art. 15 del Decreto 111/2014, de 26 de noviembre).

Por otra parte, como ya se ha señalado anteriormente, a la hora de solicitar el inicio de actividad ante el órgano competente, un requisito importante es el que las empresas de turismo activo tengan confeccionado un plan de emergencia y autoprotección o, en su caso, plan o protocolo de seguridad adecuado a las actividades que realiza (vid. Aragón o Comunidad Valenciana). A ello debe sumarse la vinculación de toda una serie de criterios de actuación que vendrán asociados a la ejecución de la correspondiente actividad. A este respecto cabe decir que los responsables de empresa, monitores/as y guías tienen la obligación de velar por la seguridad e integridad física de los usuarios o terceros presentes en el lugar. Así, las empresas deben atender a las

GARCÍA SAURA, Pilar Juana (2010): 267-285 y (2010b): 153-176; RIVERA MATEOS, Manuel (2015): 17-63; y COTS SERRA, Francesc; ROCA, Elisabet y SALLENT, Oriol (2010): 75-90.

${ }^{27} \quad$ A ello se suma la cláusula relativa al hecho de la advertencia de la posibilidad de que puedan ser modificados por circunstancias meteorológicas o imprevistos mayores. Como se comprueba, la seguridad sobre las personas es un elemento articulador en el desarrollo de las actividades contratadas. 
predicciones meteorológicas, adoptando las medidas oportunas ante alerta o activación del plan territorial de prevención ante fenómenos meteorológicos adversos; además de que los monitores o guías lleven un botiquín de primeros auxilios, un aparato de comunicación que facilite la comunicación directa tanto con los responsables de la empresa, como con los servicios públicos de emergencia y protección civil, o incluso un $\operatorname{gps}^{28}$.Como se comprueba, la vinculación con los servicios públicos de emergencia y protección civil se convierte en un elemento esencial de ahí que en Aragón las empresas tengan que remitir a Protección Civil el protocolo de actuación en caso de accidentes, la relación de las actividades y la localización de desarrollo de las mismas a los Servicios de Protección Civil o a las Fuerzas y Cuerpos de Seguridad de la zona.

Si las medidas de control para los clientes son importantes, existen otras que se deben adoptar con los clientes. Con ello, antes de la práctica de la actividad se debe repasar con ellos las normas de autoprotección y de seguridad, así como las instrucciones sobre el respeto al medio natural y cultural, y en especial las relativas a la prevención de incendios forestales (Región de Murcia). De igual manera se debe instruir sobre el desarrollo de la actividad y la utilización de los equipos y material, siempre de un modo que sea entendible por el usuario/a, advirtiendo en todo caso de la peligrosidad o grado de dificultad de los tramos y de las medidas a adoptar en caso de accidente (Comunidad Valencia, art. 12.2.c. del Decreto 22/2012, de 27 enero).

En cuanto a los usuarios es conveniente realizar diferentes apreciaciones. En primer lugar, éstos no necesariamente deben ser mayores de edad, sino que los menores pueden participar en las actividades y con ello asumir este riesgo, siempre y cuando tengan autorización previa y por escrito de quienes ostente la patria potestad o tutela legal del menor, o que al menos un mayor de edad se responsabilice del mismo (entre otras, Comunidad Foral de Navarra, art. 9 del Decreto 288/2004, de 23 de agosto). Sí que es verdad que en el caso de Andalucía, por ejemplo, el requisito de la autorización se vincula únicamente para los menores de dieciséis años (art. 30 del Decreto 20/2002, de 29 de enero), por lo que no necesariamente un menor de edad requerirá dichos condicionantes.

${ }_{28}$ Por ejemplo, Aragón (art. 11 del Decreto 55/2008, de 1 abril); Comunidad Valenciana (art. 12 del Decreto núm. 22/2012, de 27 de enero); Islas Baleares (art. 122 del Decreto núm. 20/2015, de 17 de abril.); Región de Murcia (art. 7.2 del Decreto núm. 320/2007, de 19 de octubre). En el caso de la Comunidad Valenciana, además se indica que "en el caso de que las condiciones físicas del medio en que se desarrolle la actividad no permitan la utilización de dichos aparatos de comunicación, se deberá disponer de uno en el punto más próximo posible al lugar donde se esté desarrollando la actividad" Asimismo, se exige el contar con un gps cuando se trate de actividades con itinerarios de más de diez kilómetros de longitud o que se desarrollen en áreas de una extensión superior a veinticinco kilómetros cuadrados. 
Otro aspecto a reseñar es el relativo a la facultad que tienen las empresas de turismo activo de impedir que un usuario realice la actividad. En este sentido, las regulaciones indican que las empresas de turismo activo pueden exigir unas condiciones para poder practicarlas ya no sólo de edad, sino también de estado físico y de salud, siempre y cuando estas condiciones estén justificadas dadas las características de la actividad; no obstante la regulación murciana va más allá con una normativa muy detallada que permite que los responsables de la empresa puedan limitar e incluso prohibir la participación en las actividades previstas a aquellas personas que, a consecuencia de su estado psicofísico, no estén en disposición de llevarlas a cabo con la seguridad necesaria, prohibiendo la participación a las personas que presenten síntomas manifiestos de embriaguez o de actuar bajo la influencia de las drogas ${ }^{29}$. Hay que tener en cuenta que, por ejemplo, la normativa asturiana recoge dentro del listado de obligaciones de los usuarios, el hecho de que éstos tengan que informar antes del inicio de la actividad acerca de su adecuación física para la realización de la actividad que contraten, ayudando con ello a que la empresa no incurra en cierta discrecionalidad en su decisión.

También conviene aludir a la adopción de otra serie de medidas, sobre todo relativas a la protección de medio ambiente. En este sentido, la normativa sobre turismo activo incide en que la práctica de las actividades debe producirse en condiciones compatibles con la protección del medio ambiente, hecho que al que se suma la solicitud de las autorizaciones pertinentes siempre teniendo en cuenta lo dispuesto en los planes de ordenación de recursos naturales; planes rectores de uso y gestión; planes de conservación y planes de protección de espacios naturales protegidos (Aragón). Además de todo lo anterior, los monitores o guías deben informar a los clientes ya no sólo de las normas de autoprotección y de seguridad, sino también de las medidas a adoptar para garantizar la conservación del medio natural e incluso la relativa a la prevención de incendios, añadiendo la regulación valenciana que la circulación de cualquier tipo de vehículo por terrenos forestales deberá ajustarse en todo caso a la normativa sectorial forestal ${ }^{30}$. No obstante, la vinculación con la protección del medio ambiente no es la única ya que la normativa navarra añade el respeto al patrimonio histórico cultural, debiendo solicitar ante las autoridades competentes cuantos permisos y autorizaciones sean exigibles.

${ }_{29}$ Vid. Aragón (art. 8.1 del Decreto 55/2008, de 1 abril); Comunidad Valenciana (art. 12.2.e del Decreto 22/2012, de 27 de enero); Principado de Asturias (art. 15.5 del Decreto núm. 111/2014, de 26 de noviembre) y Región de Murcia (art. 7.3 del Decreto 320/2007, de 19 octubre).

30 Vid. Andalucía (art. 29 del Decreto 20/2002, de 29 de enero); Aragón (art. 3 del Decreto 55/2008, de 1 abril); Castilla La Mancha (art. 6.5 del Decreto 77/2005, de 28 de junio); Comunidad Foral de Navarra (art. 12 del Decreto Foral 288/2004, de 23 agosto); Comunidad Valenciana (art. 14 del Decreto 22/2012, de 27 de enero); Principado de Asturias (art. 13 del Decreto 111/2014, de 26 de noviembre); Región de Murcia (art. 7 del Decreto 320/2007, de 19 de octubre). 
Estas obligaciones medioambientales de la empresa deben completarse con ciertas obligaciones de los clientes ya que los usuarios deben en todo momento mantener una conducta favorable a la conservación de los recursos naturales y culturales del medio natural, a su seguridad personal y a la del resto de los usuarios de los servicios ofrecidos. Obligación lógica que ayuda al correcto desarrollo de la activad y que a la vez se añade a otras tales como la de seguir las instrucciones de los guías y monitores, utilizar el material aportado por la empresa o la ya apuntada prohibición de llevar a cabo las actividades bajo la influencia del alcohol o de cualquier sustancia que pueda alterar el normal comportamiento de la persona.

Dentro de la relación entre empresa y cliente deben apuntarse otros aspectos importantes tales como el régimen de precios. En este sentido existe mucha discrepancia, destacándose la regulación valenciana como la más completa. Así, dicha normativa ya no sólo recoge la obligación de que los precios sean publicitados tanto en la página web, como en el interior de los locales de las empresas, ya que también se regulan otros importantes aspectos como el límite del anticipo en caso de que se pida (límite del 25\% del precio de las actividades a realizar); la necesidad de incluir en el documento de reserva las condiciones de pago y el régimen de anulación; momento de pago (tras la realización de las actividades salvo anticipo) o lo relativo al depósito por pérdida o deterioro de equipos y materiales (máximo 200 euros) ${ }^{31}$.

\section{EL TURISTA Y EL FACTOR RIESGO. RESPONSABILIDAD GIVIL DERIVADA DEL EJERCICIO DE ACTIVIDADES EN EL ÁMBITO DEL TURISMO ACTIVO}

En materia de actividades de turismo activo se puede encontrar un largo y complejo bloque jurisprudencial conexionado directamente con el ámbito de la responsabilidad extracontractual. Dichas sentencias asumen como punto de partida lo preceptuado en el art. 1902 del Código Civil por el cual aquel por acción u omisión causa daño a otro, interviniendo culpa o negligencia, está obligado a reparar el daño causado. Dicha asociación se estructura en torno a cuatro premisas como son la existencia de una acción u omisión determinante del evento dañoso y antijurídica; la producción de un daño; la existencia de dolo o negligencia atribuible al agente; y la relación de causalidad entre el daño y el hecho que la ocasiona, siendo éste imputable

31 Comunidad Valenciana (arts. 15 al 19 del Decreto 22/2012, de 27 de enero). Véase también Castilla La Mancha (art. 8 del Decreto 77/2005, de 28 junio); Comunidad Foral de Navarra (art. 12 del Decreto Foral 288/2004, de 23 agosto); Principado de Asturias (art. 11 del Decreto 111/2014, de 26 noviembre); Región de Murcia (arts. 6 y 10 del Decreto 320/2007, de 19 de octubre) 
al agente; requiriéndose todas ellas para que surja dicha obligación de resarcimiento o de indemnización ${ }^{32}$.

Como se señala en reiterada jurisprudencia, aunque de la redacción del artículo 1.902 del Código Civil se extrae el hecho de que la responsabilidad por culpa extracontractual o aquiliana se base en un elemento subjetivo de la culpa ya sea por acción u omisión, o por culpa o negligencia, este sistema ha ido evolucionando, en concreto a partir de la sentencia del Tribunal Supremo de 10 de julio de 1.943, hacia un proceso de objetivación en el cual se produce una transformación en la apreciación del principio subjetivista bien a través de la inversión o atenuación de la carga de la prueba, presumiendo culposa toda acción u omisión generadora de un daño indemnizable a no ser que el agente demuestre haber procedido con la diligencia debida a tenor de las circunstancias de lugar y tiempo; bien exigiendo una diligencia específica más alta que la administrativamente reglada ${ }^{33}$. Con todo ello, como recoge la sentencia núm. 468/2012, de 10 diciembre, de la Audiencia Provincial de Girona, para que una demanda interpuesta al amparo del art. 1902 del Código Civil pueda prosperar requiere que se acredite la concurrencia de los requisitos establecidos en dicho artículo, añadiéndose el importante matiz de la "presunción culposa de toda acción u omisión generadora de un daño indemnizable a no ser que el agente acredite haber procedido con la diligencia debida a tenor de las circunstancias de tiempo y lugar exigiendo una diligencia especifica más alta que la administrativamente reglada, entendiendo que la simple observancia de tales disposiciones no basta para exonerar de responsabilidad cuando las garantías adoptadas para prever los daños previsibles y evitables no han ofrecido resultado positivo pues revela la ineficacia del fin perseguido y la insuficiencia del cuidado prestado". De igual manera, la jurispru-

32 Véanse sentencias 150/2003, de 20 de marzo, de la Audiencia Provincial de Lleida; 433/1997, de 22 de septiembre, de la Audiencia Provincial de Burgos o 192/2004, de 19 de octubre, de la Audiencia Provincial de Huesca.

33 Sentencia núm. 367/2010, de 10 septiembre, de la Audiencia Provincial de Madrid. En concreto dicha sentencia entiende que "la simple observancia de tales disposiciones no basta para exonerar de responsabilidad cuando las garantías para prever y evitar los daños previsibles y evitables no han ofrecido resultado positivo, revelando la ineficacia del fin perseguido y la insuficiencia del cuidado prestado". Sí que es verdad la jurisprudencia, por ejemplo, el fundamento tercero de la sentencia núm. 116/2013, de 22 marzo, de la Audiencia Provincial de Santa Cruz de Tenerife, a la hora de analizar la relación causal entre el hecho (o la omisión) y el resultado lesivo opta por someter la misma a un proceso que denomina de "objetivación" en el cual "el concepto subjetivo de responsabilidad (donde el dolo y la culpa jugaban un papel preponderante) ha dejado paso a un modelo en el que el protagonismo ha dejado paso a otros factores de corte objetivo como el de riesgo inherente o el de control del mismo". Con ello se pone en línea de otros derechos como el Common Law inglés (tort of negligence), en donde se establece un deber de "prevención ante la posibilidad objetiva de un riesgo (duty of care) y donde el incumplimiento del mismo (breach of the duty of care) produce un daño (damage)", el derecho civil alemán (Körperverletzung y Gesundheitsverletzgung) o el derecho civil francés (lésion certaine d?un intèrêt légitime jurdiquement protégê). 
dencia precisa que la acción desencadenante de la obligación de resarcir precisa de una actuación imprudente, descuidada, negligente de la que deriven daños a terceras personas no ligadas por vínculos contractuales, o fuera de la órbita de estos, sin que la relación o nexo causal entre el actuar del agente y el resultado se vea interferido por ningún elemento extraño. Este es el supuesto del caso fortuito, el cual es asociado por el Tribunal Supremo, de conformidad con el art. 1105 del Código Civil, con "aquellos acontecimientos o sucesos en los que, según la medida de la diligencia requerida, sus efectos no se pueden prever o que, aun previstos, no cabe ser resistidos ni evitados, siendo más bien de procedencia interna al darse relación con el modo y circunstancias de actuar o de omitir en la persona a la que se le exigen las responsabilidades consecuentes".

Además de todo lo apuntado, sin duda el elemento clave en la responsabilidad civil derivada del ejercicio de actividades en el ámbito del turismo activo es la correlación entre la generación de determinados riesgos y la responsabilidad civil por daño, y es que como indica VIDAL GONZÁLEZ, Miguel (2013): 463-482, las causas de los accidentes son más que variadas transitando desde la utilización de equipos en mal estado o no homologados, hasta situaciones inesperadas acaecidas en el medio natural (crecidas de torrentes, barrancos, etc.).

La jurisprudencia viene determinando que en el sistema de culpa extracontractual del artículo 1902 del Código Civil "no cabe erigir el riesgo en factor único de la responsabilidad y es preciso que se dé una conducta adecuada para producir el resultado dañoso" "34. Como se ha señalado, la existencia del factor riesgo constituye un elemento básico del denominado turismo activo, hecho que si faltara privaría a la actividad de un mayor aliciente en su práctica. Todo ello conlleva que las personas que realizan dichas actividades deben ser conscientes de la existencia del mismo, ya que este hecho determinará el grado de responsabilidad de las partes ante las posibles consecuencias negativas que genere la actividad desarrollada. De igual manera debe tenerse en cuenta que los participantes de estas actividades, además de los riesgos implícitos, deben enfrentarse a situaciones inesperadas que incluso quedan fuera del control del guía o monitor en atención a los "múltiples factores variables debidos a la naturaleza del medio" en donde se desarrollan ${ }^{35}$. Este es el caso expuesto, por ejemplo, en la reciente sentencia núm. 200/2015, de 7 mayo, de la Audiencia Provincial de Lleida en el que se desestima la reclamación de indemnización por los daños y perjuicios derivados del accidente sufrido con ocasión de un vuelo en parapente

34 Vid. Sentencias del Tribunal Supremo de 22 de octubre de 1992, 20 de marzo de 1996, 20 de mayo de 1996, 14 de abril de 1999 y 17 de octubre de 2001.

35 Vid. fundamento primero de la Sentencia núm. 178/2010, de 30 julio, de la Audiencia Provincial de Huesca. 
biplaza, siendo la causa del siniestro una turbulencia. Así, el tribunal entendió que se trataba de un accidente "habitual" en este tipo de deporte de riesgo, hecho al que se suma la inexistencia de otra contribución causal del piloto en la producción del mismo, ni agravación del riesgo inherente.

Como se ha apuntado, la realización de este tipo de actividades lleva implícito un grado de riesgo que es conocido y a la vez asumido de manera voluntaria por el usuario de dichos servicios, lo cual tiene importantes consecuencias a la hora de pedir responsabilidades a la empresa en caso del acaecimiento de un accidente con daños. Claro análisis de lo anteriormente expuesto es la sentencia núm. 931/2001, de 17 octubre, del Tribunal Supremo, en donde en su fundamento de derecho cuarto se plantea si la generación de determinados riesgos puede acarrear la responsabilidad civil por daño. En el caso analizado, supuesto de fallecimiento de un participante de rafting en el transcurso de la actividad, el Tribunal Supremo determinó que se trataba de una actividad voluntaria, cuyo peligro era conocido por el solicitante, produciéndose el accidente "dentro del ámbito del riesgo asumido y aceptado" 36 . Con ello, el ejercicio de prácticas deportivas o actividades lúdicas de riesgo conlleva una aceptación y sometimiento voluntario de ese riesgo implícito, con lo que no se genera obligación de indemnizar ${ }^{37}$.

En esta misma línea se decanta la sentencia núm. 797/2009 de 30 noviembre del Tribunal Supremo, en su fundamento tercero, la cual delimita la responsabilidad de los organizadores de estas actividades. Así, la sentencia señala que "una actividad reconocida y administrativamente admitida de riesgo no puede convertir a los organizadores en responsables de todo cuanto acaezca en su desarrollo si esta se cumplimenta en un marco adecuado y previsible en cuanto a los riesgos que pudieran derivarse para el conjunto de las personas que acceden libre y espontáneamente a la misma, cuando la actividad no comporta en sí misma un riesgo anormal o considerable y no se ha producido un incremento inesperado de los riesgos esperados que permita desplazar la responsabilidad hacia quien, aun de forma lícita y permitida, crea y controla la situación de peligro". No obstante, sí que es verdad que a pesar de la configuración de la denominada "teoría del riesgo", constante jurisprudencia

\footnotetext{
36 De igual manera, la sentencia núm. 100/2005 de 30 marzo de la Audiencia provincial de Cantabria, a raíz de un accidente producido durante una excursión en quad por terrenos accidentados. Así, dicho pronunciamiento indicó que se trataba de una "actividad voluntaria, cuyo riesgo era conocido por los solicitantes, debiendo entenderse por ello que el accidente se produjo dentro del ámbito de ese riesgo asumido y aceptado" (fundamento de derecho quinto).

37 Este principio no se aplica en la Sentencia núm. 150/2003, de 20 marzo, de la Audiencia Provincial de Lleida, en la que se analiza el caso de unas lesiones sufridas por una persona que realiza rafting al arrojarse al agua para bañarse desde el bote neumático en que efectuaba la travesía por un río de aguas bravas una vez habían arribado a una zona de aguas remansadas.
} 
del Tribunal Supremo insiste en el hecho de que "el cómo y el por qué se produjo el accidente" constituyen elementos indispensables en el examen de la causa eficiente del evento dañoso y, por lo tanto, jugando un importante papel en la determinación de la relación de causalidad entre la acción u omisión culposa y el daño o perjuicio reclamado ${ }^{38}$.

Por otra parte, hay que señalar que la valoración de los riesgos implícitos hay que ponerla en correlación con la actividad. Así, actividades como el rafting, el submarinismo, el puenting o la escalada, por ejemplo, son actividades que la jurisprudencia ha venido a considerar que pueden resultar peligrosas para sus practicantes y con ello el riesgo que es asumido es mayor que en otras como puede ser la práctica del ski-bus, en donde la caída al agua es el único riesgo a considerar y que además es el objeto de dicha actividad. Así, la jurisprudencia ha venido a dictaminar que "quien acepta voluntariamente subirse en un ski-bus, porque así lo ha convenido previamente, sabe no sólo que puede caerse al agua, sino que con toda probabilidad acabará cayéndose a ella, pues en ello radica el atractivo de la diversión" "39. No obstante sí que es verdad que la jurisprudencia diferencia entre actividades con riesgo y actividades lúdicas, en donde responde el titular salvo que se acredite un mal uso por parte de la persona que utiliza la atracción ${ }^{40}$.

Con ello, parece claro que los participantes en las actividades deben asumir el riesgo asociado, siempre y cuando se desarrolle en los cauces normales y puedan controlar el mismo con la información que reciban de los organizadores y tutela de los guías o monitores no produciéndose por parte de éstos ningún incremento o agravación del riesgo asumido "ya sea por el estado de las instalaciones, por sus propias características o forma en la cual ofrecen su ejercicio, o por la inadecuación de los medios que facilita, o por la omisión de alguna de las cautelas que le son razonablemente exigibles para prevenir riesgos, de forma que no hayan agotado la diligencia necesaria en el desarrollo de la actividad que ofrecen a terceros, con quienes

38 Sentencias del Tribunal Supremo de 11 de marzo y 17 de noviembre de 1988; 27 de octubre de 1990, 25 de febrero de 1992, 21 enero y 30 junio 2000.

39 Vid. Ssentencia núm. 98/2000, de 9 marzo, de la Audiencia Provincial de Cantabria, en su fundamento segundo: "El único riesgo que existe en el «ski-bus» es la caída al agua, riesgo que constituye precisamente el objeto de la actividad, y dicha caída, de producirse, no lleva aparejada, generalmente, peligro alguno para el practicante, al llevarse a cabo con chaleco salvavidas y ser el agua un medio líquido en el que la caída desde una altura mínima - por no decir que desde la misma superficie- no suele producir lesión alguna (circunstancia que, incluso, a alguna de las partes demandadas le movió a cuestionar que las lesiones se las produjera el actor de la forma que describe)".

40 Vid. sentencia núm. 94/2005, de 7 junio, de la Audiencia Provincial de Huelva, en donde en el caso de unas lesiones sufridas por una usuaria en una atracción conocida como «La Tirolina» en un Aqupark. 
contratan, y que confían que, a pesar de todo, no sufrirán ningún tipo de daño"41. Asimismo es preciso indicar que el hecho que la actividad practicada sea de riesgo y que se produzca una exposición voluntaria al mismo, tiene como consecuencia que el interesado tenga que demostrar ante estos casos de responsabilidad que su origen es ajeno al riesgo asumido ${ }^{42}$. Ello conlleva el que además de que el usuario asume las consecuencias de la realización de la actividad, siempre y cuando el deporte se desarrolle en las condiciones normales; le incumbe demostrar lo inoportuno de realizar la actividad dada las situaciones que acontecen en ese momento ${ }^{43}$.

A modo de resumen, como expone la sentencia núm. 212/2007, de 11 junio, de la Audiencia Provincial de Las Palmas, "las actividades de riesgo asumido, eximen de responsabilidad del prestador del servicio, salvo que el actor acredite que se ha incrementado dicho riesgo por actos imputables al responsable de la actividad"44. No obstante, es importante recalcar que en la realización de las actividades, las instrucciones dadas por lo monitores o guías asumen un trascendente papel. En este sentido, sentencias como la número 31/2012, de 30 enero, de la Audiencia Provincial de Jaén, a raíz de unas lesiones durante la práctica de paintball, inciden en que debe demostrarse por el usuario que la inexistente o deficiente información facilitada es el elemento clave en la relación de causalidad y con ello la derivación de la responsabilidad hacia la empresa.

De todos modos, sí hay que advertir la necesidad de que los monitores y guías actúen conforme a la lex artis propia de sus conocimientos, dando las oportunas instrucciones y controlando el desarrollo de la actividad (sentencia del Tribunal Supremo núm. 797/2009, de 30 noviembre). A su vez, la empresa también se ve obligada a que el diseño y organización de la actividad a realizar sea adecuada, en cuanto a nivel de peligrosidad, a las personas que lo van a practicar, con lo que si no se adecúa,

41 Vid. sentencia núm. 418/2007, de 21 diciembre, de la Audiencia Provincial de Lleida y sentencia de la Audiencia Provincial de Burgos (Sección $3^{\text {a }}$ ) núm. 433/1997, de 22 septiembre.

42 Vid. fundamento primero de la Sentencia núm. 10064/2009 de 26 febrero del Tribunal Superior de Justicia de Castilla-La Mancha.

43 Sentencia núm. 575/2002, de 19 septiembre, de la Audiencia Provincial de Vizcaya, a raíz del hecho de que la sentencia dispone que al demandante le incumbe demostrar "que el día de los hechos el caudal del río Gállego aconsejaba suspender o no iniciar la actividad de descenso en balsa".

44 Dicha sentencia a su vez referencia otros pronunciamientos como las sentencias del Tribunal Supremo de 22 de octubre de 1992 en un caso de lesiones por juego de pelota, 20 de marzo -sobre accidente de esquí- y 20 de mayo de 1996 en una colisión de una lancha contra un escollo en un pantano -y 3879-, 14 de abril de 1999 -sobre accidente de parapente, todas ellas recogidas en la de 17 de octubre de 2001-en un caso de rafting con resultado de muerte -y 18 de marzo de 1999 - sobre golpe contra caseta tras deslizarse sobre un plástico, fuera de pistas; además de las sentencias de las Audiencias Provinciales de Huesca, de 6 de noviembre de 2002 -por impacto contra el tubo de una señal informativa visible, situada en el lateral de la pista, Vizcaya, Sec. 4ª 19 de septiembre de 2002 y Girona, Sec. $2^{\mathrm{a}}$, 2 de febrero de 199 con resultado de muerte. 
podría generar la responsabilidad contractual de ésta ${ }^{45}$. De igual manera conviene señalar que la falta de capacitación suficiente para la dirección de la actividad conlleva responsabilidad por culpa, tal y como señala la sentencia núm. 268/2014, de 28 mayo, de la Audiencia Provincial de Barcelona.

Por otra parte, el dolo o negligencia de los guías o monitores durante la realización de la actividad lleva consigo el que resulte probada la relación causal entre acción y daño y con ello surja la obligación de indemnización y exigible su pago. Este es el caso, por ejemplo, de las lesiones producidas a raíz de la caída y golpe contra el agua durante la realización de la atracción náutica conocida como "banana", en donde la falta de diligencia o temeridad del conductor de la motora a la hora de acelerar la velocidad del vehículo "determinó un aumento del riesgo inherente al divertimento que finalmente se concretó en el percance y en los consecuentes daños”.

Sí que es verdad que aunque anteriormente se ha señalado que el usuario al realizar voluntariamente las actividades asume un riesgo implícito, el aumento injustificado de la probabilidad de perjuicios en situaciones, como la apuntada, conlleva la acreditación de la relación causal y es que, como dice la Sentencia núm. 116/2013, de 22 marzo, de la Audiencia Provincial de Santa Cruz de Tenerife en su fundamento de derecho segundo, "siendo cosa cierta que el peligro es inherente a la vida contemporánea, existe un deber de reducción al mínimo posible los riesgos estocásticos hasta el mínimo posible, que nunca va a ser igual a cero", hecho que nada tiene que ver con el caso planteado en el cual se asiste a un aumento injustificado de la probabilidad de perjuicios.

\section{LA RESPONSABILIDAD PATRIMONIAL DE LA ADMINISTRA- CIÓN PÚBLICA}

Si anteriormente se ha analizado la responsabilidad extracontractual de las empresas de turismo activo, conviene atender de igual manera a la implicación de la Administración. Dentro de la jurisprudencia se pueden encontrar diferentes pronunciamientos que parten del hecho de que las actividades que se engloban el denominado turismo activo tienen un componente de riesgo y que quien lo practica se expone a los mismos, lo que obliga al interesado a demostrar que su origen es ajeno al riesgo asumido. En este sentido, se debe tener en consideración que para que surja la responsabilidad patrimonial es preciso que se reúnan una serie de requisitos como son "a) la efectiva realidad de un daño evaluable económicamente e individualizado

45 Vid. Sentencia núm. 100/2005, de 30 marzo, de la Audiencia Provincial de Cantabria (Sección $3^{\mathrm{a}}$ ) en su fundamento tercero: "Lo relevante en orden a determinar la existencia o no de responsabilidad por culpa contractual de "Europicos" es decidir si la ruta por la que habría de discurrir la excursión (pista forestal Ojedo-San Tirso-Trillayo-Castro-Ojedo) constituía un trazado peligroso para conductores que nunca habían pilotado un vehículo tipo "quad". 
en relación a una persona o grupo de personas; b) que el daño o lesión patrimonial sufrido por el reclamante sea consecuencia del funcionamiento normal o anormal de los servicios públicos en una relación directa, inmediata y exclusiva de causa a efecto, sin intervenciones extrañas que alteren el nexo causal; y c) que no se haya producido fuerza mayor" (sentencia del Tribunal Supremo de fecha 11 de febrero de 1991) ${ }^{46}$.

Teniendo presente lo anterior, como primer enfoque resulta interesante atender a la posibilidad de imputar responsabilidad a la Administración por daños causados por el simple hecho de ser titular del paraje donde se practica la actividad de riesgo y en donde se producen unas lesiones. Este supuesto es analizado, por ejemplo, en la Sentencia núm. 236/2011, de 14 febrero, del Tribunal Superior de Justicia de Andalucía, Granada (Sala de lo Contencioso-Administrativo, Sección 1ª) a raíz de la caída al vacío de un persona al romperse el cordino o cuerda auxiliar durante la práctica de rapel, produciéndole una paraplejia irreversible con intestinos y vejiga neurógenos. En este caso se enfrentaban dos posturas, la de la Administración que alegaba que la participación en actividades de por sí peligrosas o arriesgadas excluye la responsabilidad cuando el riesgo es asumido y aceptado por el participante y, por otra, la de la parte actora que fundaba su recurso en que la responsabilidad administrativa en el evento lo es por "culpa in vigilando" al desarrollarse la actividad en una zona con atractivo turístico que es explotada por la Administración y es la falta de diligencia la que la hacía responsable del evento y por ello obligada a atender sus consecuencias dañosas.

Ante estas posiciones discrepantes, el Tribunal descartó la existencia de responsabilidad patrimonial de la Administración ya que si bien es cierto que la titularidad del paraje implica para la Administración "los deberes de vigilancia y de conservación, lo es únicamente en relación a la protección del medio natural”. Además, el Tribunal recalcaba que también debe considerarse excluido de ese deber de vigilancia

46 Todo ello puesto en relación con los artículos 106.2 de la Constitución Española, que establece que los particulares, en los términos establecidos por la Ley, tendrán derecho a ser indemnizados por toda lesión que sufran en sus bienes y derechos salvo en los casos de fuerza mayor, siempre que la lesión sea consecuencia del funcionamiento de los servicios públicos" y 139.1 de la Ley 30/92, de Régimen Jurídico de las Administraciones Públicas y del Procedimiento Administrativo. Con ello, el Tribunal Supremo ha establecido que, para exigir la responsabilidad patrimonial por el funcionamiento de los servicios públicos, es necesario que concurran los siguientes requisitos o presupuestos: 1) hecho imputable a la Administración; 2) lesión o perjuicio antijurídico efectivo, económicamente evaluable e individualizado en relación a una persona o grupo de personas; 3) relación de causalidad entre hecho y perjuicio; y 4) que no concurra fuerza mayor u otra causa de exclusión de la responsabilidad. Así, para que nazca dicha responsabilidad es necesaria una actividad administrativa (por acción u omisión material o jurídica), un resultado dañoso no justificado y relación de causa a efecto entre aquélla y ésta, incumbiendo su prueba al que reclama; a la vez que es imputable a la Administración la carga referente a la existencia de la fuerza mayor cuando se alegue como causa de exoneración (vid. sentencia núm. 1393/2014 de 19 mayo del Tribunal Superior de Justicia de Andalucía, Granada, en su fundamento jurídico tercero). 
otros aspectos interesantes y a la par problemáticos como son la eliminación de los "elementos usados por deportistas ubicados en lugares de difícil acceso y cuya existencia se desconoce", así como la indicación a los deportistas del material que deben emplear o "cómo practicar una actividad para evitar los riesgos inherentes a ésta, lo que entra dentro de la pericia y prudencia del particular, que debe conocer bien los riesgos del deporte, la zona donde se desea practicar y las medidas de seguridad que son necesarias observar" (fundamento de derecho sexto) ${ }^{47}$.

Caso distinto resulta el hecho en que se produce una lesión como consecuencia, por ejemplo, de la caída de una piedra durante el tránsito por un sendero, en el caso planteado, de un Parque Natural. Este supuesto es analizado en la sentencia núm. 1393/2014 de 19 mayo del Tribunal Superior de Justicia de Andalucía, Granada (Sala de lo Contencioso-Administrativo, Sección $1^{\mathrm{a}}$ ) de donde se extraen interesantes aspectos. En primer lugar resulta relevante el que la sentencia considere que el hecho de que el sendero discurra por el interior del Parque y con ello se intente mantener tales espacios en su estado puro, conlleva que "la seguridad del transeúnte no siempre quede garantizada sino solo en aquellos espacios que se hayan constituido como equipamientos del Parque Natural de uso público o servicios asociados al mismo". A ello se suma el hecho de que Tribunal establece la inexistencia de responsabilidad ya que no considera la existencia del "deber de señalización y protección en todas las zonas de posible acceso humano dentro del Parque, hasta el punto de impedir la caída de piedras por causa natural o acción de animales salvajes".

Otro aspecto problemático a analizar es el relativo al funcionamiento normal o anormal de los servicios públicos, en especial puesto en relación con la intervención de los equipos de rescate. Por ejemplo, la Audiencia Nacional en su sentencia de 2 abril 2008 a raíz de una reclamación de responsabilidad patrimonial en el fallecimiento de una persona por hemorragias debido a una supuesta tardanza por parte del helicóptero de la Guardia Civil tras haber sufrido un accidente cuando practicaba parapente, concluye que "para que el daño concreto producido por el funcionamiento del servicio a uno o varios particulares sea antijurídico basta con que el riesgo inherente a su utilización haya rebasado los límites impuestos por los estándares de seguridad exigibles conforme a la conciencia social". Con ello es necesario que exista una actuación antijurídica y una relación de causalidad entre la lesión producida y el funcionamiento de los servicios públicos y en esta concatenación, el comportamiento

47 Este pronunciamiento hay que ponerlo en relación con el hecho de que la Administración sea la propietaria donde se realiza una actividad. En este sentido, la sentencia 10064/2009 de 26 febrero del Tribunal Superior de Justicia de Castilla-La Mancha, (Sala de lo Contencioso-Administrativo, Sección 2a), que se pronuncia acerca del accidente sufrido de una persona cuando practicaba "motocross" en un circuito propiedad del Ayuntamiento demandado, señala la necesidad de atender a la forma de gestión de las instalaciones deportivas que si no es por parte del Consistorio conllevará una exoneración de responsabilidad. 
de la víctima juega un papel fundamental. Con ello, "la prueba de la concurrencia de acontecimientos de fuerza mayor o circunstancias demostrativas de la existencia de dolo o negligencia de la víctima suficiente para considerar roto el nexo de causalidad" corresponde a la Administración (fundamento de derecho tercero).

\section{TASA POR MOVILIZACIÓN DE EFEGTIVOS Y MEDIOS DE EMERGENCIA}

Para concluir este estudio relativo a la vinculación del turismo activo con las situaciones de riesgo, es interesante abordar otro aspecto como es la denominada tasa por la prestación de determinados servicios de búsqueda, rescate y salvamento. Hay que considerar que esta tasa se ha ido incorporando progresivamente en algunas Comunidades Autónomas, basándose en el hecho de inculcar una "cultura preventiva" en la población a la hora de la realización de prácticas deportivas y/o de ocio que puedan entrañar riesgo. Lo que se pretende al fin y al cabo es apelar a la responsabilidad de los usuarios para que éstos, a la hora de realizar las actividades, se aseguren de adoptar las máximas garantías de seguridad ${ }^{48}$.

Profundizando en los aspectos más importantes de esta tasa asociada a situaciones acaecidas como consecuencia de la práctica de actividades recreativas o deportivas que entrañen riesgo o peligro para el sujeto pasivo ${ }^{49}$, el hecho imponible se basa en la prestación, por razones de seguridad pública, de los servicios de rastreo, rescate o salvamento, independientemente que los mismos se produzcan de oficio o a requerimiento de parte, pero siempre que la prestación del servicio redunde en beneficio de quien tenga la consideración de sujeto pasivo. Conviene señalar que el hecho imponible se asocia a que la prestación de tales servicios se produzca como consecuencia del acaecimiento de una serie de circunstancias ya prefijadas que, por ejemplo, la norma canaria, y en parecido sentido la regulación vasca, vincula ya no

48 En este sentido, es interesante la información dada por el Gobierno de Canarias en su folleto informativo sobre tasas por la prestación de determinados servicios de búsqueda, rescate y salvamento. Este documento puede consultarse en la web de la Dirección General de Seguridad y Emergencias. Consejería de Economía, Hacienda y Seguridad Gobierno de Canarias. http://www.gobiernodecanarias.org/dgse/ descargas/folleto_tasas.pdf (mayo de 2016).

49 Vid. Art. 111.bis del Decreto Legislativo 1/2007, de 11 septiembre, por el que se aprueba el texto refundido de la Ley de Tasas y Precios Públicos de la Administración de la Comunidad Autónoma del País Vasco: "A los efectos de la aplicación de esta tasa se considerarán actividades recreativas y deportivas que entrañan riesgo o peligro para las personas las siguientes, así como sus distintas modalidades y estilos: submarinismo, travesía de natación, windsurfing, flysurf, esquí acuático, wakeboard, wakesurf, skurfer, motos de agua, bodyboard, surf, rafting, hydrospeed, piragüismo, remo, descenso de cañones y barrancos, puenting, goming, kite buggy, quads, escalada, espeleología deportiva o «espeleismo», bicicleta en montaña sin casco protector, motocross, vehículos de motor en montaña, raid y trec hípico, marchas y turismo ecuestre, esquí, snowboard, motos de nieve, paraski, snowbike, mushing, skibike, aerostación, paracaidismo, salto base, vuelo de ultraligeros, vuelo en aparatos con motor y sin motor, parapente, ala delta y parasailing". 
sólo a que la situación de emergencia se produzca como consecuencia de la práctica de una actividad recreativa o deportiva que entrañe riesgo o peligro para quien lo practica, a lo que se añade un listado de actividades deportivas y recreativas consideradas peligrosas o arriesgadas y que conlleva a que se cobre el rescate con o sin negligencia o imprudencia por parte del implicado ${ }^{50}$, sino también en una serie de supuestos como cuando la búsqueda, rescate o salvamento se deba bien a que la persona no observó y cumplió las advertencias de peligro, prohibiciones u obligaciones de conducta convenientemente ubicadas en zonas de riesgo; se hubiera realizado una actividad o un uso prohibido en espacios naturales protegidos o sin la debida autorización administrativa; cuando la búsqueda, rescate o salvamento de una persona se deba a la situación de peligro en la que ésta se encuentra por realizar una actividad contraria a las precauciones, instrucciones, avisos u orientaciones la dirección general competente en materia de emergencias o cualquier organismo oficial competente en materia de protección civil haya emitido como consecuencia de una situación de alerta; cuando la persona que realiza una actividad no disponga del equipamiento adecuado para su correcto desarrollo; o en los casos en que no era necesaria tal movilización de medios, pero se hizo atendiendo a la información o solicitud de la persona, o cuando el beneficiario o, en general, cualquier persona, falsee o simule una situación de emergencia ${ }^{51}$.

Excluyendo situaciones de catástrofe o calamidad pública, así como razones de interés general y no en beneficio de particulares o de bienes determinados, las regulaciones sobre la materia consideran como sujeto pasivo a aquellos que organicen las actividades recreativas y deportivas que dieran lugar a la prestación de los servicios, en este caso las empresas de turismo activo, estableciéndose como responsables subsidiarios a las personas físicas o jurídicas que sean beneficiarias de la prestación del servicio. No obstante, conviene matizar un aspecto y es que en el supuesto de que el sujeto pasivo tenga contratada una póliza de seguro que cubra estas situaciones, serán sujetos pasivos sustitutos las entidades o sociedades aseguradoras. Con ello, el

50 Como ocurre en la regulación vasca, la normativa canaria considera peligrosas o arriesgadas las siguientes actividades deportivas y recreativas. Acuáticas: submarinismo, travesía de natación, windsurfing, flysurf, esquí acuático, wakeboard, wakesurf, skurfer, motos de agua, bodyboard, surf, rafting, hydrospeed, piragüismo, remo. Terrestres: descenso de cañones y barrancos, puenting, goming, kite buggy, quads, escalada, espeleología deportiva, espeleismo, bicicleta de montaña, motocross, vehículos de motor en montaña, raid y trec hípico, marchas y turismo ecuestre, esquí, snowboard, paraski, snowbike. Aéreas: aerostación, paracaidismo, salto base, vuelo de ultraligeros, vuelo en aparatos con motor y sin motor, parapente, ala delta y parasailing.

51 Art. 44 de la Ley 4/2012, de 25 de junio, de medidas administrativas y fiscales, que modifica el Texto refundido de las disposiciones legales vigentes en materia de tasas y precios públicos de la Comunidad Autónoma de Canarias aprobado por Decreto Legislativo 1/1994, de 29 de julio. Así se crea un nuevo título XIII (arts. 171 y ss.). 
importe de la cuota de la tasa tendrá como límite la suma asegurada en la póliza por este concepto, y, en su defecto, el límite establecido como suma aseguradora para el conjunto de la prestación.

En cuanto a la cuota de la tasa, ésta se determina atendiendo, por una parte, al número de efectivos personales profesionales y medios materiales que intervengan en la prestación del servicio, y, por otra, al tiempo invertido en la prestación del servicio por cada uno de los efectivos y medios, devengándose la misma en el momento en que se inicie la prestación del servicio, que coincidirá con la salida de la correspondiente dotación; no obstante, por ejemplo en la regulación canaria en el caso de que la actividad de rescate se inicie de oficio, la tasa se devenga en el momento en que comienza la efectiva realización de los trabajos. Las cuotas de la tasa por rastreo, rescate o salvamento varían sustancialmente entre Comunidades autónomas, ya no sólo por la cuantía (euro/ hora), sino sobre todo por el catálogo de medios humanos y personales que caso por caso fijan su importe. A ello se suma el hecho de que la primera hora, que comprende los derechos de salida, se estipula su devengo completo (vid. Principado de Asturias) y a partir de la misma su liquidación de forma proporcional ${ }^{52}$.

Para finalizar, otro aspecto a analizar es el relativo a qué ocurre ante los casos en que la persona buscada y rescatada fallece. En este caso, por ejemplo la normativa canaria opta por el hecho de que si la persona buscada y rescatada fallece con anterioridad a la activación de los recursos, no habrá obligación de pago de tasa. Sin embargo, en el caso de que fallezca posteriormente a la prestación del servicio, se transmitirá la obligación de pago a las personas herederas. A ello se suma la circunstancia de que en el supuesto de fallecimiento o extinción de la persona obligada al pago de la tasa por sustitución (organizador de la actividad) o por ser responsable solidario (asegurador), no se producirá la transmisión de la deuda.

52 Por ejemplo en el País Vasco (art. 111 del Decreto Legislativo 1/2007, de 11 septiembre): medios humanos (por cada persona): 36 euros/hora; medios materiales: por cada vehículo: 38 euros/hora; por cada helicóptero: 2.093 euros/hora; por cada embarcación (con eslora menor o igual a 18 metros: 383 euros/hora, con eslora superior a 18 metros: 2.017 euros/hora). Principado de Asturias (art. 156 noveno de la Ley 11/2014, de 29 diciembre, de presupuestos generales para 2015); servicios prestados por el personal de intervención: titulado superior 16,50 € / hora, titulado grado medio 13,50€ / hora, jefe supervisor 18,90 $€$ / hora, jefe de zona 17,30 € / hora, bombero - conductor 14,00 € / hora, bombero - rescatador 14,10 $€$ / hora auxiliar de bombero especialista 11,60€ / hora; medios técnicos, vehículos ligeros (vehículos de mando, de transporte de personal y todo terreno de patrullaje) y otros: $36,10 €$ / hora; medios técnicos y vehículos pesados (vehículo multisocorro, autobomba urbana, autobomba forestal y autobomba nodriza): 209,00 € / hora; medios técnicos y vehículos especiales (autoescalera, brazo articulado, vehículo de apoyo logístico y puesto de mando avanzado): 439,00 € / hora; medios técnicos y helicóptero multifunción: $1.258,30 €$ / hora; medios técnicos y helicóptero medicalizado: 2.027,30€ / hora. 


\section{CONSIDERACIONES FINALES}

La cada vez mayor potenciación de nichos de mercado en España con el objeto de mantener a nuestro país en las primeras posiciones de destinos turísticos, conlleva en muchos casos el surgimiento de un producto sin el adecuado respaldo legal.

El turismo activo se enfrenta desde su aparición a un problema normativo como consecuencia de las especiales peculiaridades que presenta. El hecho de la realización de actividades en la naturaleza conlleva que los controles sobre las empresas de turismo activo sean férreos con el objeto de asegurar una esfera adecuada de protección al turista entendida ya no sólo en el aspecto contractual, sino sobre todo en el desarrollo de la actividad con la exigencia de equipos y materiales homologados, una formación adecuada de los monitores e instructores o el que se disponga de los correspondientes seguros y planes de actuación ante situaciones de peligro. En este sentido, se ha comprobado en este estudio la existencia de una variada jurisprudencia en torno a la responsabilidad civil derivada del ejercicio de actividades. Así, el que el turista asuma de antemano un factor riesgo en la ejecución de éstas, determina en gran manera la responsabilidad de la empresa ante los sucesos acaecidos.

Por otra parte, la conexión del turismo activo con otras legislaciones sectoriales hace que la perspectiva de análisis no pueda circunscribirse única y exclusivamente a la esfera turística, sino que la empresa tendrá que atender a las peculiaridades normativas según el ámbito y clases de actividades que oferte. Ello supone un problema añadido en cuanto a las licencias o permisos con los que deberá contar para poder operar en el mercado, pero, por otra parte, asegura la sostenibilidad del elemento esencial sobre el que se basa este turismo, es decir, el medio natural.

Para finalizar, la potenciación del turismo de interior en sus distintas modalidades (turismo rural, turismo fluvial, etc.) arrastra consigo la necesidad de una adaptación de la normativa a las nuevas necesidades, sobre todo por la aparición continua de nuevas actividades o propuestas turísticas a desarrollar en el entorno natural. Resulta curioso como todavía algunas Comunidades Autónomas carecen de legislación específica sobre turismo activo, hecho que de nada ayuda a un sector clave para la economía española y que puede debilitar la imagen del destino España en cuanto al compromiso de las Administraciones públicas con el mismo. 


\section{BIBLIOGRAFÍA}

ADVENTURE TRAVEL TRADE ASSOCIATION, Industry Snapshot. Adventure Travel Trade Association. Seattle, 2013

ASPAS ASPAS, José Manuel, Los deportes de aventura: consideraciones jurídicas sobre el turismo activo. Editorial Prames. Zaragoza, 2000.

BEARD, Colin; SWARBROOKE, John; LEGKIE, Suzanne y POMFRET, Gill, Adventure Tourism. Elsevier. Oxford, 2003.

BERMEJO LATRE, José Luis y ESCARTÍN ESCUDÉ, Víctor, "El impacto de la reforma de servicios en el sector del turismo", en MOREU CARBONELL, Elisa (coord.), El impacto de la directiva Bolkestein y la reforma de los servicios en el derecho administrativo, Monografías de la Revista Aragonesa de Administración Pública, núm. XII, Zaragoza, 2010, págs. 495-512.

BUGKLEY, Ralf, Adventure Tourism Management. Elsevier. Oxford, 2010.

COTS SERRA, Francesc; ROCA, Elisabet y SALLENT, Oriol. "Turismo activo y sostenibilidad en Cataluña. Una valoración desde el sector privado”, en Estudios turísticos núm. 183, 2010, págs. 75-90.

ESTORNELL PONS, María, "Aproximación al léxico del turismo activo: codificación lexicográfica, formación y variación denominativa", en Normas. Revista de estudios lingüísticos hispánicos núm. 3, 2003, págs. 33-55.

GARCÍA SAURA, Pilar Juana, "Análisis del régimen jurídico-medioambiental del turismo activo en España”, en Revista Aranzadi de derecho ambiental núm. 18, 2010, págs. 267-285;

GARCÍA SAURA, Pilar Juana, "Turismo activo y medio ambiente: una implicación necesaria. Aspectos jurídicos”, en Cuadernos de turismo núm. 26, 2010b, págs. 153176.

GONZÁLEZ MENORCA, Carlos; GONZÁLEZ MENORCA, María Leonor;JUANEDA AYENSA, Emma y PELEGRÍN BORONDO, Jorge, La calidad en las organizaciones turísticas. Editorial Paraninfo. Madrid, 2014, págs. 69 y ss.

LACOSTA ARAGÜÉS, Antonio Javier, "La configuración de nuevos destinos turísticos de interior en España a partir del turismo activo y de aventura (19922001)", en Cuadernos Geográficos núm. 34, 2004, págs. 11-31;

MELGOSA ARCOS, Francisco Javier, "Turismo rural y turismo activo", en MELGOSA ARCOS, Francisco Javier (coord.), Estudios de derecho y gestión ambiental, Vol. 1. Fundación Cultural Santa Teresa. Ávila, 1999, págs. 477-502. 
MELGOSA ARCOS, Francisco Javier, "La regulación del turismo en España. El nuevo marco jurídico tras la directiva de servicios de mercado interior”, en MELGOSA ARCOS, Francisco Javier (coord.), Turismos de interior: planificación, comercialización y experiencias. Editorial Pirámide, Madrid, 2013, págs. 73-96.

NASARRE SARMIENTO, José María, "Propuestas para una convergencia de la regulación jurídica de las empresas de turismo activo", en Acciones e Investigaciones Sociales, núm. 31, 2012, págs. 233-263

PADRÓS I REIG, Carlos y MACÍAS CASTAÑO, José María, "Los instrumentos administrativos de garantía de la unidad de mercado, en Revista de administración pública, núm. 194, 2014, págs. 113-151.

PEÑALVER TORRES, María Teresa, "El turismo activo como alternativa y complemento al modelo turístico en la Región de Murcia”, en Cuadernos de Turismo, núm. 14, 2004, págs. 179-215.

RIVERA MATEOS, Manuel, "El tratamiento de las actividades de turismo activo en los instrumentos de planificación ambiental de los parques naturales andaluces", en Revista de estudios regionales núm. 102, 2015, págs. 17-63.

TORNOS MAS, Joaquín, "La ley 20/2013, de 9 de diciembre, de garantía de la unidad de mercado. En particular, el principio de eficacia", en Revista d'estudis autonòmics ifederals, núm. 19, 2014, págs. 144-177.

VIDAL GONZÁLEZ, Miguel, "Turismo activo", en MELGOSA ARCOS, Francisco Javier (coord.), Turismos de interior: planificación, comercialización y experiencias. Editorial Pirámide, Madrid, 2013, págs. 463-482.

VILA FRADERA, Jorge, La gran aventura del turismo en España. Ediciones Turísticas. Barcelona, 1997. 